\title{
Severe L-asparaginase-induced Hypertriglyceridaemia Treated with Plasmapheresis
}

\author{
José Silvano, Nidia Marques, Isabel Tavares, Ines Ferreira \\ Nephrology Department, Centro Hospitalar e Universitário de São João, Porto, Portugal
}

Doi: 10.12890/2021_002342 - European Journal of Case Reports in Internal Medicine - ( ) EFIM 2020

Received: 31/01/2021

Accepted: 02/02/2021

Published: 18/02/2021

How to cite this article: Silvano J, Marques N, Tavares I, Ferreira I. Severe L-asparaginase-induced hypertrigyceridaemia treated with plasmapheresis. EJCRIM 2021;8: doi:10.12890/2021_002342.

Conflicts of Interests: The Authors declare that there are no competing interests.

This article is licensed under a Commons Attribution Non-Commercial 4.0 License

\section{ABSTRACT}

L-asparaginase is used for the treatment of acute lymphoblastic leukaemia. Hypertriglyceridaemia is a side effect and associated with potentially fatal complications, including acute pancreatitis. Plasmapheresis may have a role in treatment when triglycerides are $>2000 \mathrm{mg} /$ dl.

We report the case of a 39-year-old woman treated with L-asparaginase for acute lymphoblastic leukaemia, who developed severe hypertriglyceridaemia $(6560 \mathrm{mg} / \mathrm{dl})$ and acute pancreatitis. Intravenous insulin infusion was started, along with fenofibrate and atorvastatin administration, and platelet transfusion. Plasmapheresis was carried out leading to a frank decline in serum triglyceride levels (366 mg/dl), a decrease in pancreatic enzymes and clinical improvement.

The diagnosis of pancreatitis secondary to L-asparaginase should lead to immediate drug withdrawal, and plasmapheresis should be considered when serum triglyceride values exceed $2000 \mathrm{mg} / \mathrm{dl}$. In our case, there was a 95\% triglyceride removal rate. This response illustrates the strong effectiveness of early treatment with plasmapheresis in severe and symptomatic hypertriglyceridaemia associated with L-asparaginase.

\section{LEARNING POINTS}

- Pancreatitis following L-asparaginase-induced hypertriglyceridaemia is a severe and potentially reversible condition in both adults and children treated for acute lymphoblastic leukaemia.

- Early plasmapheresis is more effective to rapidly decrease serum triglycerides.

\section{KEYWORDS}

L-asparaginase, hypertriglyceridemia, pancreatitis, plasmapheresis

\section{INTRODUCTION}

L-asparaginase is administered as part of remission induction chemotherapy for acute lymphoblastic leukaemia ${ }^{[1]}$. It acts by converting L-asparagine to aspartic acid, thus depriving the leukaemic cell of asparagine. Total cholesterol and triglyceride (TG) elevation, as well as coagulopathy, are known side effects ${ }^{[2]}$. The pathogenic mechanism involved seems to be related to increased very-low-density lipoprotein (VLDL) levels and chylomicron synthesis, as well as decreased lipoprotein lipase activity. Hypertriglyceridaemia (HTG) is associated with potentially fatal complications, including acute pancreatitis ${ }^{[2]}$. Pancreatitis is well described in the paediatric population but is rare in adults $^{[3]}$. The standard management of this complication has not yet been properly established. 
Plasmapheresis (PLF) may have a role when TG levels are $>2000 \mathrm{mg} / \mathrm{dl}$, and/or if the patient is clinically symptomatic, in order to rapidly reduce serum concentrations ${ }^{[4]}$.

\section{CASE DESCRIPTION}

A 39-year-old woman, with a medical history of lower right limb thrombophlebitis and acute coronary syndrome of vasospastic aetiology, was diagnosed with Philadelphia chromosome-negative acute lymphoblastic leukaemia. She started therapy with a regimen which included prednisolone, clorafabine and L-asparaginase. After the first administration of L-asparaginase, she complained of nausea and epigastric abdominal pain radiating to the back. Due to the persistence of pain, which was refractory to analgesia, an abdominal ultrasound was performed that revealed hepatic steatosis and a pancreas without morphological abnormalities. Laboratory tests showed hypofibrinogenaemia (99 $\mathrm{mg} / \mathrm{dl})$, thrombocytopenia $\left(15,000 \times 10^{9} / \mathrm{l}\right)$, lipase elevation (511 U/l), hyponatraemia (131 mEq/l), HTG (6560 mg/dl) and total cholesterol elevation $(697 \mathrm{mg} / \mathrm{dl})$. A diagnosis of acute pancreatitis secondary to HTG precipitated by L-asparaginase was made.

Intravenous insulin infusion was started, along with fenofibrate and atorvastatin administration, and platelet transfusion. Due to the severe and symptomatic HTG, PLF was prescribed with replacement of 1 plasma volume with fresh frozen plasma, given the increased risk of haemorrhage. In the following 24 hours, there was a frank decline in serum TG levels $(366 \mathrm{mg} / \mathrm{dl}$ ) and in pancreatic enzymes, as well as marked clinical improvement with resolution of abdominal pain. Figure 1 shows the milky effluent obtained during the first PLF session. A second PLF session was performed 3 days after the first, due serum TG re-elevation ( $>500 \mathrm{mg} / \mathrm{dl}$ ). No new PLF sessions were needed, and the patient was discharged with no further recurrence of symptoms.

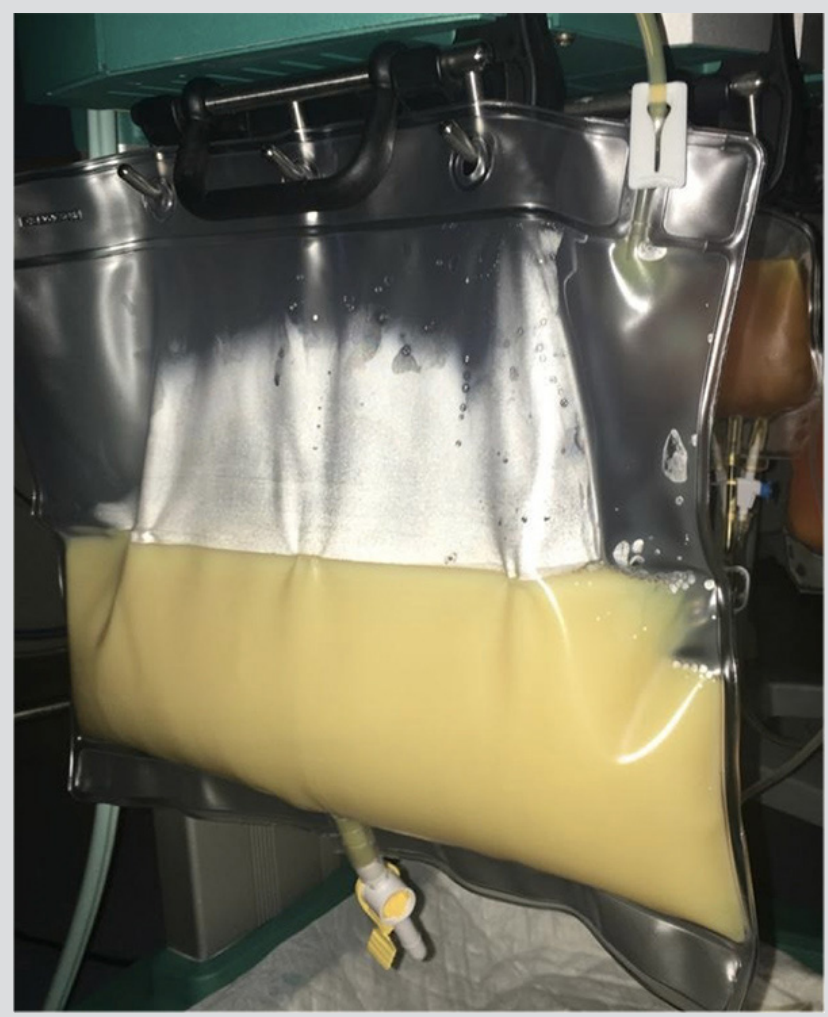

Figure 1. Milky effluent after the first plasmapheresis session

\section{DISCUSSION}

The diagnosis of pancreatitis secondary to L-asparaginase administration should result in immediate drug withdrawal and PLF should be considered when serum TG values exceed $2000 \mathrm{mg} / \mathrm{dl}^{[4]}$. The amount of PLF required has not been completely established, but replacement of 1-1.5 plasma volumes with $5 \%$ albumin or fresh frozen plasma is recommended ${ }^{[5]}$. The extracorporeal removal rate of TG is estimated to be around $66 \%$ by the end of the first session ${ }^{[4]}$. In our case, there was a $95 \%$ removal rate, normalization of serum lipase, and complete resolution of symptoms. This response illustrates the strong effectiveness of early treatment with PLF in severe and symptomatic HTG associated with L-asparaginase. 


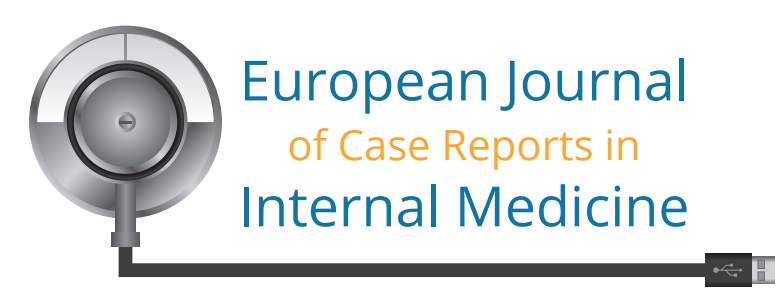

In conclusion, clinicians should be aware of this possible complication in patients treated with L-asparaginase, as well as the need for rapid referral to appropriate treatment which may include PLF.

\section{REFERENCES}

1. Abshire TC, Pollock BH, Billett AL, Bradley P, Buchanan GR. Weekly polyethylene glycol conjugated L-asparaginase compared with bi-weekly dosing produces superior induction remission rates in childhood relapsed acute lymphoblastic leukemia: a Pediatric Oncology Group Study. Blood 2000;96(5):1709-1715.

2. Bhojwani D, Darbandi R, Pei D, Ramsey LB, Chemaitilly W, Sandlund JT, et al. Severe hypertriglyceridaemia during therapy for childhood acute lymphoblastic leukaemia. Eur J Cancer 2014;50(15):2685-2694.

3. Wlazłowski M, Celiñska W, Maciejka-Kapuœciñska LP, Łoszyñska A, Idczak E. Acute pancreatitis in children with acute lymphoblastic leukemia treated with L-asparaginase. Pol Tyg Lek 1994;49(12-13):296-297.

4. Kfoury-Baz EM, Nassar RA, Tanios RF, Otrock ZK, Youssef AM, Albany C, et al. Plasmapheresis in asparaginase-induced hypertriglyceridemia. Transfusion 2008;48(6):12271230.

5. Rawla P, Sunkara T, Thandra KC, Gaduputi V. Hypertriglyceridemia-induced pancreatitis: updated review of current treatment and preventive strategies. Clin J Gastroenterol 2018;11(6):441-448. 